\title{
Assessment of HRV After Maximal Exercise in Trained Postmenopausal Women
}

\author{
J. C. ORRI ${ }^{1}$, E. M. HUGHES ${ }^{1}$, D. G. MISTRY ${ }^{1}$, A. SCALA ${ }^{1}$ \\ ${ }^{1}$ Department of Kinesiology, University of San Francisco, San Francisco, CA, USA
}

Received December 31, 2017

Accepted April 13, 2018

On-line July 25, 2018

\section{Summary}

Increased parasympathetic tone achieved with endurance training may provide cardioprotection after menopause. To compare heart rate variability (HRV) from rest through maximal exercise and recovery in trained postmenopausal women. Thirtysix postmenopausal women who self-reported training at either moderate (MOD; 3-5.9 METS; 58.9 \pm 4.4 year) or vigorous (VIG; $>6$ METS; 59.7 \pm 5.2 year) intensities participated. HRV was measured for $5 \mathrm{~min}$ in the supine position, in the last minute of the $\mathrm{VO}_{2}$ max test and after 2 min of active recovery. HRV in MOD and VIG was compared using a factorial ANOVA with repeated measures on time. MOD and VIG responded similarly over the three time periods for root mean square of sequential deviations (rMSSD), and high (HF) and low frequency (LF) power ( $p>0.05$ ). Maximal exercise lowered rMSSD (3.3 \pm 0.08 vs. $1.2 \pm 0.06)$ and $\operatorname{InLF}(4.1 \pm 0.05$ vs. $3.3 \pm 0.13)$ and increased InHF ( $3.3 \pm 0.14$ vs. $4.0 \pm 0.10 ; \mathrm{p}<0.01)$ from resting. However, active recovery restored $\operatorname{InHF}(3.3 \pm 0.11)$ and $\operatorname{InLF}(4.1 \pm 0.08)$ from maximal values $(p<0.01)$. Our findings suggest that moderate and vigorous exercise training may enhance HRV recovery following one bout of maximal exercise in older women.

\section{Key words}

Menopause $\bullet$ Training intensity $\bullet$ Cardioprotection

\section{Corresponding author}

Julia C. Orri, Department of Kinesiology, University of San Francisco, 2130 Fulton St., San Francisco, CA 94117, USA. Fax: (415) 422-6040. E-mail: jorri@usfca.edu

\section{Introduction}

An imbalance favoring sympathetic tone has been shown to increase cardiovascular disease risk in postmenopausal women (Gautam et al. 2011). A noninvasive measure of autonomic nervous system dysfunction is heart rate variability (HRV). As women transition through menopause, augmented sympathetic function has been shown to result in vascular damage and increased mortality (Sanchez-Barajas et al. 2015). This loss of parasympathetic dominance and corresponding arrhythmia protection is reflected by changes in the high frequency power domain of HRV (Tsuji et al. 1994).

Although HRV declines with age, physically active women have higher HRV than sedentary women (Davy et al. 1998). Reland et al. (2003) reported an enhanced sinus node response to incremental exercise in the highly active group compared to low and moderate, suggesting that exercise intensity may attenuate the effects of age on cardiovascular disease risk. Additionally, post-exercise HRV dynamics (vagal reactivation) have been shown to be intensity-dependent (Kaikkonen et al. 2007).

Assessment of HRV post-exercise is a valuable tool to monitor autonomic nervous system (ANS) dysfunction and potential cardiac abnormalities (Pecanha et al. 2017). The normal increase in heart rate during exercise occurs through parasympathetic withdrawal and reduced HRV. However, a prolonged delay in the restoration of $\mathrm{HRV}$ can predispose the heart to arrhythmias (Brown and Brown 2007).

The purpose of this study was to compare the HRV response from rest through maximal exercise and recovery in trained postmenopausal women. 


\section{Methods}

\section{Participants}

The study design has been described in detail elsewhere (Orri et al. 2017). Briefly, thirty-six postmenopausal women volunteered from the community. The women self-reported their exercise training intensity as either (1) Vigorous - masters level swimmers, cyclists or runners who trained $>6$ METS (metabolic equivalents of oxygen); or (2) Moderate recreational swimmers or cyclists who trained at 3-6 METS. All women were exercising at their level for a minimum of 6 months prior to enrolling in the study (Thompson 2010). The Institutional Review Board at the University approved the study protocol. Written consent was obtained from all participants.

\section{Exclusion criteria}

Women who were taking $\beta$-blockers or antiarrhythmic drugs were excluded due to their effect on heart rate variability. All women were healthy, with one or fewer risk factors for cardiovascular disease according to the American College of Sports Medicine (ACSM) (Thompson 2010). Women who were taking hormone therapy (HT) were enrolled due to the lack of influence of estrogen on HRV as shown by Harvey et al. (2015). There were five women in the MOD group who were taking HT and 1 in the VIG group. As such, two analyses were performed on the CRP and HRV data, one with the HT performers included, and the other without. It was found that HT did not influence these outcome variables.

\section{Procedures}

The measurements were performed at the Exercise Physiology Laboratory at the University at least $24 \mathrm{~h}$ following the participants' last regular exercise bout. They were asked to refrain from ingesting food, alcohol, or caffeine within three hours of testing (Thompson 2010). Testing time was not standardized due to lack of flexibility in participant's and laboratory schedules.

\section{Aerobic capacity}

A heart rate monitor (Polar RS800cx, Finland) transmitter was placed on the participant's chest and a receiver (watch) was attached to their wrist. For the resting HRV assessment, participants lay supine for 5 min during normal breathing. After the heart rate stabilized, the HRV was measured for 5 min (Seiler et al. 2007). Following the resting measurements, participants had their $\mathrm{VO}_{2} \max$ measured on the treadmill using the Bruce protocol. Expired gases were collected continuously using a calibrated metabolic cart (ParvoMedics True Max 2400, Sandy UT, USA). The criteria for $\mathrm{VO}_{2} \max$ were one of the following: failure of heart rate to increase with further increases in exercise intensity, a plateau in oxygen uptake or failure to increase oxygen uptake by $150 \mathrm{ml} \cdot \mathrm{min}^{-1}$ with increased workload, a respiratory exchange ratio $>1.1$, or a rating of perceived exertion (RPE) $>17$ on the 6-20 scale (Thompson 2010).

Following the exercise test, subjects walked at a self-selected pace $(2.0 \mathrm{mph})$ for five minutes. Heart rate variability was measured at $\mathrm{VO}_{2} \max$, and minutes 1 and 2 following cessation of exercise. The heart rate recovery (HRR) was calculated by subtracting the heart rate at minutes 1 and 2 from HRmax.

\section{Outcome measures}

The HRV analysis included mean heart rate, mean RR (interbeat) interval, the root mean square of sequential deviations (rMSSD), and the percentage of all sequential RR deviations exceeding $50 \mathrm{~ms}$ (pNN50) in the time domain, plus high (HF) and low frequency (LF) power in the frequency domain (Seiler et al. 2007).

\section{Statistical analysis}

Normality was checked with the Shapiro-Wilk test. Variables with a skewed distribution were logtransformed prior to analysis. Comparison of HRV in MOD and VIG was performed using a factorial ANOVA with repeated measures on time. The level of significance was set at $p<0.05$. Statistical analyses were performed using IBM SPSS Statistics 20.0.

\section{Results}

Table 1 shows the anthropometric and $\mathrm{VO}_{2} \max$ data. Of the 18 women in the VIG group, there were 13 master swimmers, 2 competitive rowers, 2 cyclists and 1 runner. The MOD group had 14 recreation swimmers, 1 runner, and 3 women who worked out at the gym (elliptical, walking). The VIG group had higher waist circumference compared to MOD $(p<0.05)$. Heart rate recovery was equal and rapid in both MOD and VIG $(p>0.05)$. No other differences were found $(p>0.05)$.

There were no differences between MOD and VIG for resting HRV $(p>0.05)$. Figure $1(a, b, c)$ shows that maximal exercise lowered $\operatorname{lnLF}$ (log transformed value of low frequency) and rMSSD and increased lnHF 
from resting. Two minutes of active recovery on the treadmill significantly restored both frequency indices from maximal values $(\mathrm{p}<0.01)$. Figure 2 is an example of $\mathrm{HRV}$ for one VIG participant at preexercise, $\mathrm{VO}_{2} \mathrm{max}$ (time $=11: 18$ ) and active recovery. There is greater variability in the RR interval preexercise with a corresponding lower heart rate. As the participant approaches $\mathrm{VO}_{2}$ max there is a reduced HRV at a higher heart rate.

Table 1. Anthropometric and $\mathrm{VO}_{2}$ max data.

\begin{tabular}{lcc}
\hline & Moderate (MOD; n=18) & Vigorous (VIG; n=18) \\
\hline Age (year) & $58.9 \pm 4.4$ & $59.7 \pm 5.2$ \\
BMI $\left(\mathrm{kg} / \mathrm{m}^{2}\right)$ & $23.0 \pm 2.7$ & $24.6 \pm 3.0$ \\
WC $(\mathrm{cm})$ & $74.1 \pm 5.0$ & $81.3 \pm 9.6^{\mathrm{a}}$ \\
BF $(\%)$ & $23.8 \pm 4.7$ & $24.5 \pm 3.9$ \\
VO ${ }_{2} \max (\mathrm{ml} / \mathrm{kg} / \mathrm{min})$ & $32.4 \pm 5.7$ & $34.5 \pm 5.1$ \\
HRmax (bpm) & $163.9 \pm 10.6$ & $162.1 \pm 10.9$ \\
HRR $\min 1(\mathrm{bpm})$ & $24.4 \pm 9.3$ & $22.7 \pm 9.0$ \\
HRR $\min 2(\mathrm{bpm})$ & $43.4 \pm 9.6$ & $45.2 \pm 11.4$ \\
\hline
\end{tabular}

All values are mean $\pm \mathrm{SD}$; unadjusted values. MOD, trained at 3.0-5.9 METS; VIG, $\geq 6.0$ METS; BMI, body mass index; WC, waist circumference; BF, body fat; RHR, resting heart rate; HRR, heart rate recovery. ${ }^{a} p<0.01$.
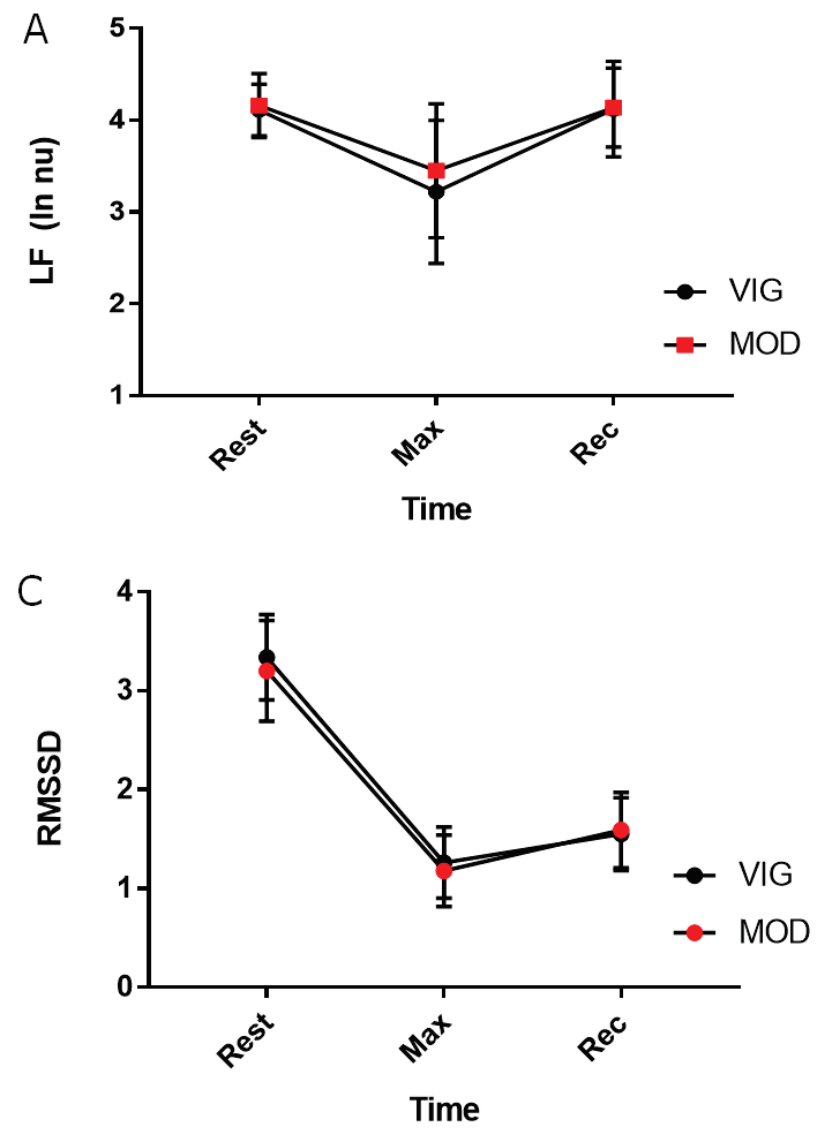

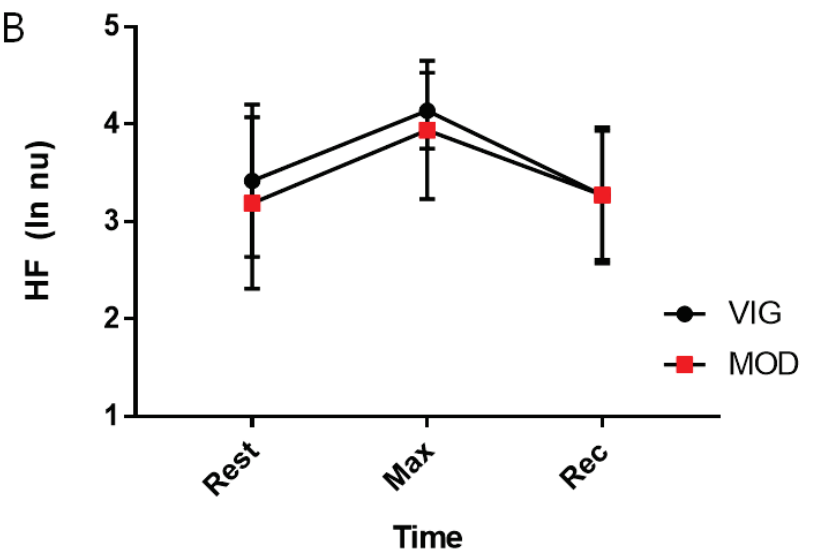

Fig. 1. The effect of maximal exercise and recovery on (A) LF, (B) HF and (C) rMSSD (logarithmic transformed). (HF, high frequency; LF, low frequency; rMSSD, root mean square of sequential deviations). 


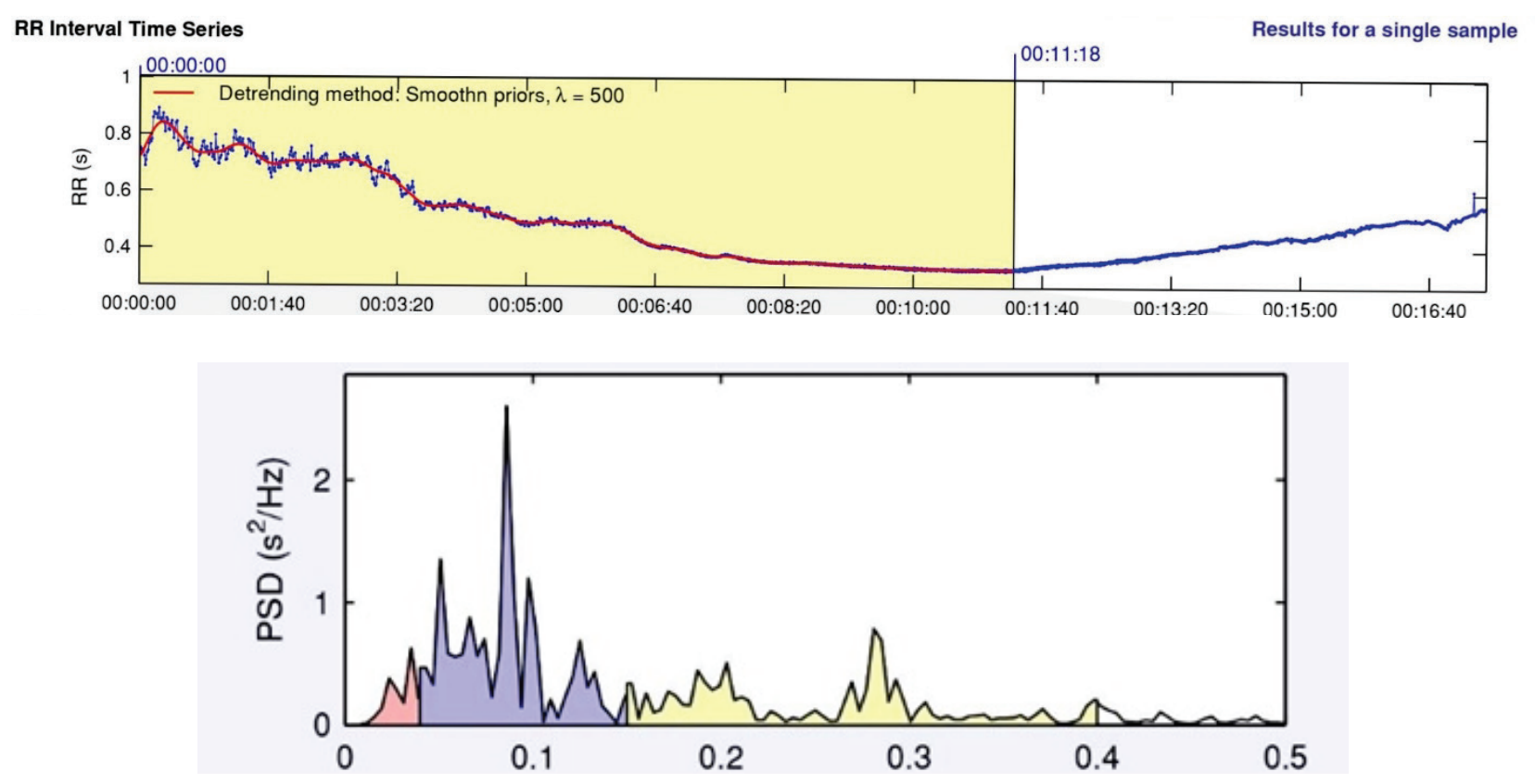

Fig. 2. An example of $\mathrm{HRV}$ for one VIG participant at preexercise, $\mathrm{VO}_{2} \max (11: 18)$ and active recovery. (A) Corrected RR interval time series; (B) Frequency histogram at preexercise, $\mathrm{VO}_{2} \max (11: 18)$ and active recovery. (FFT, fast Fourier transform; PSD, power spectrum density; Welch's periodgram: 256 window with $50 \%$ overlap).

\section{Discussion}

This observational study showed that vigorous exercise was similar to moderate over the three time periods for rMSSD, and high and low frequency power values. Frequency domain variables returned to baseline values by $2 \mathrm{~min}$ after maximal exercise in both MOD and VIG. To our knowledge, this is one of the few studies to investigate HRV during maximal exercise and recovery in trained postmenopausal women.

The LF decrease at $\mathrm{VO}_{2}$ max was equal between groups. Our findings are in accordance with Perini et al. (2002) who reported decreases in LF above $0.7 \mathrm{l} / \mathrm{min}$ during the graded cycle ergometer test following 8 weeks of aerobic training in men $(75.1 \pm 4.0$ year) and women (72.9 \pm 3.2 year). Cottin et al. (2008) reported that decreases in LF may be as result of vagal withdrawal and saturation of the cardiac $\beta$-receptors by catecholamines. Our results are in line with a study by Bailon and colleagues (2013) who found a similar LF decrease, followed by a rapid increase during recovery in young men. Imai et al. (1994) also found similar results in young athletes, and suggested that training status influences vagal recovery. In the present study, despite self-reporting their training status, both MOD and VIG had cardiorespiratory fitness levels that were at or above the "good" levels, as determined by ACSM (Thompson, 2010). These results suggest that training at or above
6 METS has a positive influence on vagal reactivation during postmenopause.

We also found an increase in $\mathrm{HF}$ at $\mathrm{VO}_{2} \max$, with no difference between groups. The HF component reflects the respiratory effort of the performer and is an indicator of the vagal activity of the heart (Vanderlei et al. 2009). Our findings are contrary to Reland et al. (2003) who reported decreases in HF only in their active group who self-reported their physical activity $(3,445 \pm 409.3 \mathrm{kcal} /$ week $)$. They further added that training intensity did not affect respiratory drive. Our participants had higher $\mathrm{VO}_{2}$ max levels (MOD 32.4 \pm 5.7 ; VIG $34.5 \pm 5.1 \mathrm{ml} / \mathrm{kg} / \mathrm{min}$ ) that were directly measured with expired gases. Previous studies have suggested HF increases were a result of hyperventilation and mechanical stretching of the sinus node (Cottin et al. 2008). Blain et al. (2005) reported that the periodic stretching of the sinus node seen during intense exercise occurs independent of pressure influences on the atria (Blain et al. 2005). Freeman (2006) hypothesized that the interplay between parasympathetic and sympathetic control may be due to baroreceptor function.

In the present study, two minutes of active recovery restored the HRV frequency indices to resting values. The HRV values in our study were reestablished much quicker than in previous studies on older men and women. Our results are also in contrast to Harvey et al. (2016) who reported a delay in ANS recovery after 
$45 \mathrm{~min}$ of treadmill exercise at $60 \% \mathrm{VO}_{2}$ peak, in sedentary postmenopausal women and no effect of exercise in premenopausal women. Our participants exercised at over $100 \%$ of age-predicted max heart rate (MOD 163.9, VIG $162.1 \mathrm{bpm}$ ) with a heart rate recovery of over $70 \%$ after $2 \mathrm{~min}$. The ability to restore autonomic modulation is imperative, given the association with cardiac arrhythmias post-exercise (Brown and Brown 2007).

The efficacy of HRV in the prediction of sudden cardiac death is well-documented (Huikuri et al. 1999). As women transition through menopause, they experience an immediate decrease in HRV from the loss of estrogen's influence on cross bridge formation and cardiac contractility (Brockbank et al. 2000). Further, women experiencing hot flushes have been shown to have increased sympathetic dominance and reduced parasympathetic tone as the low estrogen affects the central nervous system (Hautamaki et al. 2011). In spite these cardiac changes, the influence of HT on HRV has been equivocal. Perseguini et al. (2014) reported that the women not undergoing HT had improved HRV, through reduced sympathetic and increased parasympathetic modulation, compared to the participants who were taking HT. In our study, we found no differences in the HRV outcome variables, despite five women in the MOD group who were on HT. Given the lack of consistency of benefit of HT on HRT, along with the findings of the Women's Health Initiative (Rossouw et al. 2002), the importance of endurance training throughout the aging process cannot be understated. Okazaki et al. (2005) found that the HRV of masters athletes was similar to young control subjects. Further, their sedentary group increased their HRV after 1 year of training. The authors concluded that the enhanced HRV could potentially lower the risk of ventricular fibrillation.

The reductions in HRV with age may only be partially offset with regular exercise. In a recent large cross-sectional study, Jandackova et al. (2016) reported that there was an age-dependent reduction in HRV, with no additional benefit of maintaining a physical activity level as suggested by the World Health Organization.
However, the authors pointed out that the decreases in HRV indices such as standard deviation of normal RR intervals (SDNN) and LF were augmented in women experiencing cardiometabolic pathologies. A study by Uusitalo et al. (2004) found decreases in LF after 5 years of low intensity aerobic training (40-60\% $\left.\mathrm{VO}_{2} \mathrm{max}\right)$ in older men (57.4 year). It is important to mention that their population was equally distributed between healthy and men with cardiovascular or other conditions requiring medication. The effect of detraining on HRV was explored by Sotiriou et al. (2013). They found that former professional soccer players who maintained their aerobic fitness had higher HRV time and frequency indices compared to inactive former athletes and controls. Moreover, the authors stressed that the improvements in autonomic modulation were essentially lost despite previous intensive training and competition at the elite level.

In the present study, we demonstrated that the essential component to maintaining autonomic modulation throughout the aging process is an active lifestyle. Our VIG participants were competitive in swimming, rowing and cycling. Although most of our MOD participants were not performing interval training, their dedication to exercise resulted in cardioprotective benefits. Our results suggest that these lifestyle choices are crucial to the enhancement of HRV through and beyond menopause.

\section{Conflict of Interest}

There is no conflict of interest.

\section{Acknowledgements}

We are grateful for the time and effort that our participants put forth during data collection and personal workouts. We are also grateful for the assistance of the undergraduates in the Exercise and Disease Prevention class at the University of San Francisco for their feedback and support throughout the pilot testing of this study. Faculty Development Fund, College of Arts and Sciences, University of San Francisco.

\section{References}

BAILON R, GARATACHEA N, DE LA IGLESIA I, CASAJUS JA, LAGUNA P: Influence of running stride frequency in heart rate variability analysis during treadmill exercise testing. IEEE Trans Biomed Eng 60: 1796-1805, 2013.

BLAIN G, MESTE O, BERMON S: Influences of breathing patterns on respiratory sinus arrhythmia in humans during exercise. Am J Physiol Heart Circ Physiol 288: H887-H895, 2005. 
BROCKBANK CL, CHATTERJEE F, BRUCE SA, WOLEDGE RC: Heart rate and its variability change after the menopause. Exp Physiol 85: 327-330, 2000.

BROWN SJ, BROWN JA: Resting and postexercise cardiac autonomic control in trained master athletes. J Physiol Sci 57: 23-29, 2007.

COTTIN F, MÉDIGUE C, PAPELIER Y: Effect of heavy exercise on spectral baroreflex sensitivity, heart rate, and blood pressure variability in well-trained humans. Am J Physiol Heart Circ Physiol 295: H1150-H1155, 2008.

DAVY KP, DESOUZA CA, JONES PP, SEALS DR: Elevated heart rate variability in physically active young and older adult women. Clin Sci 94: 579-584, 1998.

FREEMAN JV, DEWEY FE, HADLEY DM, MYERS J, FROELICHER VF: Autonomic nervous system interaction with the cardiovascular system during exercise. Prog Cardiovasc Dis 48: 342-362, 2006.

GAUTAM S, SHANKAR N, TANDON OP, GOEL N: Comparison of cardiac autonomic functions among postmenopausal women with and without hormone replacement therapy, and premenopausal women. Indian J Physiol Pharmacol 55: 297-303, 2011.

HARVEY PJ, O'DONNELL EO, PICTON P, MORRIS BL, NOTARIUS CF, FLORAS JS: After-exercise heart rate variability is attenuated in postmenopausal women and unaffected by estrogen therapy. Menopause 23: 390-395, 2015.

HAUTAMAKI H, PIIRILA P, HAAPALAHTI P, TUOMIKOSKI P, SOVIJARVI AR, YLIKORKALA O, MIKKOLA TS: Cardiovascular autonomic responsiveness in postmenopausal women with and without hot flushes. Maturitas 68: 368-373, 2011.

HUIKURI HV, MAKIKALLIO T, AIRAKSINEN KE, MITRANI R, CASTELLANOS A, MYERBURG RJ: Measurement of heart rate variability: A clinical tool or a research toy? $J$ Am Coll Cardiol 34: 1878-1883, 1999.

IMAI K, SATO H, HORI M, KUSUOKA H, OZAKI H, YOKOYAMA H, TAKEDA H, INOUE M, KAMADA T: Vagally mediated heart rate recovery after exercise is accelerated in athletes but blunted in patients with chronic heart failure. J Am Coll Cardiol 24: 1529-1535, 1994.

JANDACKOVA VK, SCHOLES S, BRITTON A, STEPTOE A: Are changes in heart rate variability in middle-aged and older people normative or caused by pathological conditions? Findings from a large population-based longitudinal cohort study. J Am Heart Assoc 5: 1-13, 2016.

KAIKKONEN P, NUMMELA A, RUSKO H: Heart rate variability dynamics during early recovery after different endurance exercises. Eur J Appl Physiol 102: 79-86, 2007.

OKAZAKI K, IWASAKI K, PRASAD A, PALMER MD, MARTINI ER, FU Q, ARBAB-ZADEH A, ZHANG R, LEVINE BD: Dose-response relationship of endurance training for autonomic circulatory control in healthy seniors. J Appl Phys 99: 1041-1049, 2005.

ORRI J, HUGHES E, MISTRY D, SCALA A: Is vigorous exercise training superior to moderate for CVD risk after menopause? Sports Med Int Open 1: E166-E171, 2017.

PECANHA T, BARTELS R, BRITO LC, PAULA-RIBEIRO M, OLIVEIRA RS, GOLDBERGER JJ: Methods of assessment of the post-exercise cardiac autonomic recovery: A methodological review. Int $J$ Cardiol 227: 795-802, 2017.

PERINI R, FISHER N, VEICSTEINAS A, PENDERGAST DR: Aerobic training and cardiovascular responses at rest and during exercise in older men and women. Med Sci Sports Exerc 34: 700-708, 2002.

PERSEGUINI NM, DE MEDEIROS TAKAHASHI AC, MILAN JC, DOS SANTOS PR, NEVES VFC, BORGHISILVA A, SILVA E, MONTANO N, PORTA A, CATAI AM: Effect of hormone replacement on cardiac autonomic modulation. Clin Auton Res 24: 63-70, 2014.

RELAND S, VILLE NS, WONG S, GAUVRIT H, KERVIO G, CARRE F: Exercise heart rate variability of older women in relation to level of physical activity. J Gerontol A Biol Sci Med Sci 58: 585-591, 2003.

ROSSOUW JE, ANDERSON GL, PRENTICE RL, LACROIX AZ, KOOPERBERG C, STEFANICK ML, JACKSON RD, BERESFORD SA, HOWARD BV, JOHNSON KC, KOTCHEN JM, OCKENE J, WRITING GROUP FOR THE WOMEN'S HEALTH INITIATIVE INVESTIGATORS: Risks and benefits of estrogen plus progestin in healthy postmenopausal women: principal results from the Women's Health Initiative randomized controlled trial. JAMA 288: 321-333, 2002. 
SÁNCHEZ-BARAJAS M, FIGUEROA-VEGA N, DEL ROCÍO IBARRA-REYNOSO L, MORENO-FRÍAS C, MALACARA JM: Influence of heart rate variability and psychosocial factors on carotid stiffness, elasticity and impedance at menopause. Arch Med Res 46: 118-126, 2015.

SEILER S, HAUGEN O, KUFFEL E: Autonomic recovery after exercise in trained athletes: Intensity and duration effects. Med Sci Sports Exerc 39: 1366-1373, 2007.

SOTIRIOU P, KOUIDI E, SAMARAS T, DELIGIANNIS A: Linear and non-linear analysis of heart rate variability in master athletes and healthy middle-aged non-athletes. Med Eng Phys 35: 1676-1681, 2013.

THOMPSON WR: ACSM's Guidelines for Exercise Testing and Prescription. Philadelphia: Wolters Kluwer/Lippincott Williams \& Wilkins, 2010, $380 \mathrm{p}$.

TSUJI H, VENDITTI FJ JR, MANDERS ES, EVANS JC, LARSON MG, FELDMAN CL, LEVY D: Reduced heart rate variability and mortality risk in an elderly cohort. The Framingham heart study. Circulation 90: 878-883, 1994.

UUSITALO ALT, LAITINEN T, VÄISÄNEN SB, LÄNSIMIES E, RAURAMAA R: Physical training and heart rate and blood pressure variability: a 5-yr randomized trial. Am J Physiol Heart Circ Physiol 286: H1821-H1826, 2004.

VANDERLEI LC, PASTRE CM, HOSHI RA, CARVALHO TD, GODOY MF: Basic notions of heart rate variability and its clinical applicability. Rev Bras Cir Cardiovasc 24: 205-217, 2009. 